\title{
Mast Cells Induce Migration of Dendritic Cells in a Murine Model of Acute Allergic Airway Disease
}

\author{
Sebastian Reuter $^{\mathrm{a}} \quad$ Nina Dehzad $^{\mathrm{a}}$ Helen Martin $^{\mathrm{a}}$ Anke Heinz ${ }^{\mathrm{a}}$ Timo Castor $^{\mathrm{c}}$ \\ Stephan Sudowe ${ }^{c}$ Angelika B. Reske-Kunz ${ }^{c}$ Michael Stassen ${ }^{b}$ Roland Buhla \\ Christian Taube ${ }^{a}$
}

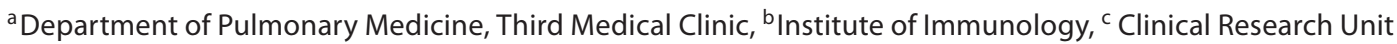
Allergology, Department of Dermatology, Johannes Gutenberg University Mainz, Mainz, Germany

\section{Key Words}

Asthma - Inflammation - Mast cells - Dendritic cells •

Murine model

\begin{abstract}
Background: The migration of dendritic cells (DCs) from the lungs to the regional lymph nodes is necessary for the development of allergic airway disease. Following activation, mast cells release a variety of stored or de novo-produced inflammatory mediators, several of them being capable of activating DCs. In this study, the role of mast cells on DC migration from the lungs to the thoracic lymph nodes was investigated in sensitized mice. Methods: Mast cell-deficient mice (Kit ${ }^{W}$ sh/W-sh) and their wild-type counterparts were sensitized intraperitoneally with ovalbumine (OVA) in saline and challenged by a single intranasal administration of OVA labeled with a fluorescent dye (OVA-Alexa). Results: Following challenge, the relative and absolute amount of OVAAlexa-positive DCs was clearly increased in sensitized wildtype mice compared to nonsensitized mice. In contrast, sensitized $\mathrm{Kit}^{\mathrm{W}}$-sh/W-sh showed no increase in OVA-Alexa-positive DCs compared to nonsensitized mast cell-deficient animals. In sensitized $\mathrm{Kit}^{\mathrm{W} \text {-sh/W-sh }}$ mice reconstituted with bone marrow-derived mast cells (BMMCs), the number of OVAAlexa-positive DCs was comparable to that in sensitized wild-
\end{abstract}

type animals. However, transfer of allergen-exposed BMMCs to sensitized mice prior to airway challenge augmented airway inflammation similarly in wild-type and mast cell-deficient mice. In line with this, sensitization with allergen-pulsed DCs induced allergic airway disease independently of mast cells. Conclusions: This study shows an interaction between mast cells and DCs following allergen challenge in sensitized hosts. However, the function of mast cells can be bypassed in models utilizing activated allergen-exposed DCs to initiate the development of allergic airway disease.

Copyright $\odot 2009$ S. Karger AG, Basel

\section{Introduction}

Asthma is a complex airway disease characterized by chronic inflammatory changes of the airway walls. During the development of the disease, manifold interactions between resident and invading inflammatory cells occur. Animal models have helped to reveal important pathways involved in allergic airway disease [1]. One of the identified pathogenetic mechanisms involves mast cells, which are found in increased numbers in the airways of patients with asthma [2]. In murine models, mast cells have been linked to the induction of airway inflammation and hyperresponsiveness (AHR) [3, 4]. Following

\section{KARGER}

Fax +41613061234 E-Mail karger@karger.ch www.karger.com
(C) 2009 S. Karger AG, Basel

$1018-2438 / 10 / 1513-0214 \$ 26.00 / 0$

Accessible online at:

www.karger.com/iaa
Correspondence to: Dr. Christian Taube

Department of Pulmonary Medicine, Third Medical Clinic

Johannes Gutenberg University Mainz

Langenbeckstrasse 1, DE-55101 Mainz (Germany)

Tel. +496131 17 6848, Fax +496131 17 6668, E-Mail taube@3-med.klinik.uni-mainz.de 
cross-linking of the high-affinity IgE receptor, mast cells release a wide variety of mediators, including lipid mediators, cytokines and chemokines [5]. In sensitized hosts, mast cell activation and mast cell-derived mediators like histamine and tumor necrosis factor (TNF) are critical for inflammation and AHR [6-8]. Increased migration of $\mathrm{T}$ cells into the lung and their local activation have been proposed as potential mechanisms [7], but mediators produced by mast cells might also directly affect dendritic cell (DC) activation and their migration to lymphoid tissue [5].

DCs are the most potent primary antigen-presenting cells in the lung, where they form a sentinel network beneath the epithelial surface [9]. They are able to detect and take up exogenous materials, process these antigens and present them to $T$ cells in the draining lymph nodes. Depending on surface receptor expression and maturation status, DCs can be divided into different subtypes in the lung. Myeloid (mDCs) and plasmocytoid DCs (pDCs) [10] have been investigated most often. DC activation and migration to the regional lymph nodes are critical steps for the development of allergic airway disease in sensitized hosts. In the absence of mDCs, all features of allergic airway disease are abrogated [11], whereas pDCs have been shown to be negative regulators for the development of allergic disease [12].

Mast cells and their activation have been linked to activation and migration of antigen-presenting cells from the skin [13]. Moreover, mediators produced by mast cells may be involved in the regulation of DC migration from the lung to the regional lymphoid tissue $[14,15]$. Therefore, we studied the migration of DCs from the lung to the regional lymph nodes in already sensitized mast cell-deficient animals following airway challenge. We conclude that following allergen exposure of a sensitized host, activated mast cells can alter the pulmonary micro-milieu and induce antigen uptake, activation and migration of DCs.

\section{Materials and Methods}

\section{Mice}

$\mathrm{WB} / \mathrm{ReJ}-\mathrm{W} /^{+}$and $\mathrm{C} 57 \mathrm{BL} / 6 \mathrm{~J}-\mathrm{W}^{\mathrm{v} /+}$ mice were received from Jackson Laboratory (Sulzfeld, Germany) and the mast cell-deficient c-kit mutant $\mathrm{F}_{1}$ generation mice $\mathrm{WBB} 6 \mathrm{~F}_{1}-\mathrm{Kit}^{\mathrm{W} / \mathrm{Wv}}$ and the congenic $\mathrm{WBB} \mathrm{F}_{1}-\mathrm{Kit}^{+/+}$were bred in the Zentrale Tierzuchtanstalt of Johannes Gutenberg University Medical Center. Additionally, mast cell-deficient $\mathrm{C} 57 \mathrm{BL} / 6-\mathrm{Kit}^{\mathrm{W}-\mathrm{sh} / \mathrm{W} \text {-sh }}$ mice and their congenic C57BL/6- $\mathrm{Kit}^{+/+}$wild-type littermates were obtained by intercrossing C57BL/6-Kit ${ }^{\mathrm{W}-\mathrm{sh} /+}$ mice kindly provided by Marcus Maurer (Department of Dermatology, Charité, Berlin, Germany). C57BL/6 mice were obtained from the Zentrale Tierzuchtanstalt of Johannes Gutenberg University Medical Center. All mice were used at the age of 8-12 weeks. Animal experiments were conducted in accordance with current federal, state and institutional guidelines.

\section{Experimental Protocols}

Mice were sensitized by intraperitoneal injections of $100 \mu \mathrm{l}$ solution containing $20 \mu \mathrm{g}$ of ovalbumin (OVA, Sigma-Aldrich, St. Louis, Mo., USA) in phosphate-buffered saline (PBS) on days 0 and 14. On day 28, mice were anesthetized (ketamine-ratiopharm ${ }^{\circledR} /$ Rompun $2 \%$ ) (Ratiopharm, Ulm, Germany/Bayer, Leverkusen, Germany) and challenged intranasally with $80 \mu \mathrm{g}$ fluorescent-labeled OVA (Alexa Fluor 647, MoBiTec, Goettingen, Germany). At 4, 24 and $48 \mathrm{~h}$ following the challenge, tracheal and inguinal lymph nodes were collected and single cell suspensions were stained for FACS analysis.

Preparation of Lymph Node Single Cell Suspensions and FACS Staining

Lymph nodes were mechanically disrupted and then digested with collagenase II ( $1 \mathrm{mg} / \mathrm{ml}$, Worthington, Lakewood, N.J., USA). Cells were then washed and counted. To quantify mDC populations, the cells were stained with FITC-labeled antiMHCII (eBioscience, San Diego, Calif., USA) and PE-labeled antiCD11c (BD Bioscience, Rembodegen, Belgium). To distinguish between mDCs, pDCs and B cells, the cells were additionally stained with PercP-Cy5-labeled anti-B220 (BD Bioscience). Among B220-negative cells, the number of Alexa 647-positive cells was determined. The absolute numbers of each cell type were calculated using total cell count and percentages.

\section{Mast Cell Reconstitution}

To obtain bone marrow-derived mast cells (BMMCs), bone marrow from C57BL/6 mice was cultured for 4-5 weeks in modified Iscove's Modified Dulbecco's Medium (IMDM, 10\% FCS, 50 $\mu \mathrm{M} \beta$-mercaptoethanol, $2 \mathrm{mM}$ glutamine, $100 \mu \mathrm{g} / \mathrm{ml}$ streptomycin, $100 \mathrm{U} / \mathrm{ml}$ penicillin, kit ligand, IL-3) as previously described $[8,13]$. After 4 weeks of culture, $>95 \%$ of nonadherent cells contained granules that stained positive with toluidine blue, and $>95 \%$ expressed c-Kit on their surface as determined by FACS analysis using an anti-c-Kit monoclonal antibody (BD Bioscience). To reconstitute the mast cell-deficient mice (6-week-old $\left.\mathrm{C} 57 \mathrm{BL} / 6-\mathrm{Kit}^{\mathrm{W}-\mathrm{sh} / \mathrm{W} \text {-sh }}\right), 5 \times 10^{6} \mathrm{BMMCs}$ were injected into the tail vein of each mouse. The mice were used for the experiments 8 weeks after the injection.

\section{Adoptive Transfer of Antigen-Pulsed Bone Marrow-Derived}

DCs

Bone marrow-derived DCs (BMDCs) were generated according to a previously published protocol [16]. Bone marrow cells were grown in culture medium (IMDM, 10\% FCS, $50 \mu \mathrm{M} \beta$-mercaptoethanol, $2 \mathrm{mM}$ glutamine, $100 \mu \mathrm{g} / \mathrm{ml}$ streptomycin, 100 $\mathrm{U} / \mathrm{ml}$ penicillin supplemented with $5 \%$ of granulocyte-monocyte colony-stimulating factor (GM-CSF)-containing cell culture supernatant derived from X63.Ag8-653 myeloma cells stably transfected with a murine GM-CSF expression construct, a kind gift from Dr. B. Stockinger, National Institute for Medical Research, London, UK). On day 8, the cells were pulsed with $100 \mu \mathrm{g} / \mathrm{ml}$ OVA (Grade V, Sigma/Aldrich, Deisenhofen, Germany). Untreated BMDCs were used as a control. Before administration, cells were washed and suspended in PBS to a concentration of $12.5 \times$ 
$10^{6}$ cells $/ \mathrm{ml}$. Purity and activation status of the DCs were determined by FACS. In the first model, mice were sensitized by intraperitoneal injections of $20 \mu \mathrm{g}$ OVA on days 0 and 14 . On day 28 , the mice were anesthetized by intraperitoneal injections of ketamine hydrochloride (ketamine, Ratiopharm) and xylazine hydrochloride (Rompun, Bayer), and $1 \times 10^{6}$ antigen-pulsed BMDCs were administered intranasally in a volume of $80 \mu \mathrm{lPBS}$. All animals received a single intranasal OVA challenge $(20 \mu \mathrm{l}$, $5 \mathrm{mg} / \mathrm{ml}$ in saline) on day 29. Two days following the challenge, bronchoalveolar lavage (BAL) was performed. In the second model, $1 \times 10^{6}$ BMDCs were administered intranasally to nonsensitized mice according to a previously described protocol [17]. On days $10-12$, mice were challenged by inhalation with an OVA solution (1\% in PBS) for 20 min. One day following the last challenge, airway reactivity was measured and BAL was performed.

\section{Measurement of Airway Reactivity}

Measurement of airway resistance (RL) and dynamic compliance $\left(\mathrm{C}_{\mathrm{dyn}}\right)$ was performed on anesthetized, intubated and mechanically ventilated mice (Flexivent, Scireq, Montreal, Que., Canada) as previously described [8]. The respiratory tract was stimulated with rising doses $(6.25,12.5,25,50$ and $100 \mathrm{mg} / \mathrm{ml}$ PBS) of methacholine. Measurements of the RL and $\mathrm{C}_{\text {dyn }}$ were performed every $15 \mathrm{~s}$ following nebulization with each single dose until a plateau phase was reached.

\section{Bronchoalveolar Lavage}

After assessment of airway function, lungs were lavaged via the tracheal tube with PBS $(1 \times 1 \mathrm{ml})$. Numbers of BAL cells were counted by trypan blue exclusion. Differential cell counts were made from cytocentrifuged preparations fixed and stained with the Microscopy Hemacolor ${ }^{\circledR}$ Set (Merck, Darmstadt, Germany). Percentages of each cell type were assessed. The absolute numbers of each cell type were calculated using total cell count and percentages.

\section{Histology}

Lungs were fixed by inflation $(1 \mathrm{ml})$ and immersion in $10 \%$ formalin and embedded in paraffin. Tissue sections were stained with hematoxylin and eosin (HE), periodic acid-Schiff (PAS) and toluidine blue. To assess reconstitution efficiencies, sections were used for fluorescence staining of tissue specific for mast cells with avidin-Alexa 488 (Molecular Probes, Eugen, Oreg., USA) [8, 13, $18,19]$. Slides were examined in blinded fashion by 2 experienced observers with a microscope (BX40, Olympus, Hamburg, Germany); peribronchial inflammation was graded with a semiquantitative score (no inflammation $=0-4$ ) [20]. For each slide, 5 randomly chosen areas were scored. The number of goblet cells on PASstained slides was analyzed using imaging software (Soft Imaging Systems, Stuttgart, Germany). The number of mucus-containing cells per millimeter basement membrane was determined [20].

\section{Statistical Analysis}

To determine the levels of differences between all groups, nonparametric ANOVA (Kruskal-Wallis test) was used to assess overall differences. In case of a significant result, the Mann-Whitney $\mathrm{U}$ test was used to elucidate which specific differences were statistically significant. Differences in responsiveness to methacholine were assessed by repeated-measures ANOVA. p $<0.05$ was considered statistically significant. Values for all measurements are expressed as the means \pm SEM.

\section{Results}

\section{Mast Cells Regulate the Migration of DCs from the} Lung to the Regional Lymph Nodes following Allergen Exposure in Sensitized Mice

Administration of fluorescent-labeled antigen OVAAlexa Fluor 647 led to detectable numbers of mDCs (MHC II+ CD11c+ B220-) in the bronchial lymph nodes $24 \mathrm{~h}$ later (fig. 1a). In sensitized and challenged wild-type animals, the relative and absolute number of fluorescentlabeled mDCs was significantly higher at $24 \mathrm{~h}$ following OVA administration compared to nonsensitized wildtype animals (fig. 1a, b). The numbers of fluorescent-labeled $\mathrm{mDCs}$ were significantly $(\mathrm{p}<0.05)$ lower in sensitized mast cell-deficient $\mathrm{C} 57 \mathrm{BL} / 6-\mathrm{Kit}^{\mathrm{W}}{ }^{\mathrm{H}} \mathrm{s} / \mathrm{W}$-sh mice than in sensitized wild-type mice and comparable to nonsensitized animals.

Similar results were obtained in a different strain of mast cell-deficient mice $\left(\mathrm{WBB} \mathrm{F}_{1}-\mathrm{Kit}^{\mathrm{W} / \mathrm{Wv}}\right)$. Again, in sensitized wild-type controls, increased numbers of fluorescent-labeled $\mathrm{mDC}$ were detectable at $24 \mathrm{~h}$ following allergen exposure, whereas in sensitized $\mathrm{WBB}_{6} \mathrm{~F}_{1}-\mathrm{Kit}^{\mathrm{W} / \mathrm{Wv}}$ mice, the numbers of fluorescent-labeled $\mathrm{mDCs}$ were similar to those in nonsensitized control animals (data not shown).

\section{In Mast Cell-Deficient Mice, Migration of mDCs Is}

Restored following Transfer of Mast Cells

Previous studies have demonstrated that mast cell-deficient mice can develop allergic airway disease following transfer of BMMCs $[7,8]$. Taking advantage of this technique, we examined the effect of mast cell transfer on the migration of DCs from the lung to the regional lymph nodes. Similar to previous results [8], transfer of BMMCs derived from wild-type animals to C57BL/6-Kit ${ }^{\mathrm{W}-s h / W-s h}$ mice restored mast cell numbers in genetically mast celldeficient animals (table 1). Following sensitization and challenge, C57BL/6-Kit ${ }^{\mathrm{W}-\mathrm{sh} / \mathrm{W} \text {-sh }}$ mice reconstituted with wild-type mast cells showed significantly higher numbers of fluorescent mDCs compared with sensitized but not reconstituted $\mathrm{C} 57 \mathrm{BL} / 6-\mathrm{Kit}^{\mathrm{W}-\mathrm{sh} / \mathrm{W} \text {-sh }}$ animals and challenged, only reconstituted $\mathrm{C} 57 \mathrm{BL} / 6-\mathrm{Kit}^{\mathrm{W}-\mathrm{sh} / \mathrm{W} \text {-sh }}$ animals, but comparable numbers to those in sensitized wild-type animals (fig. 2).

\section{Transfer of Allergen-Exposed DCs to Sensitized Mice Prior to Airway Challenge Augments Airway Inflammation in Mast Cell-Deficient Mice}

As a measure of the inflammatory response in the lungs following sensitization and challenge, we deter- 

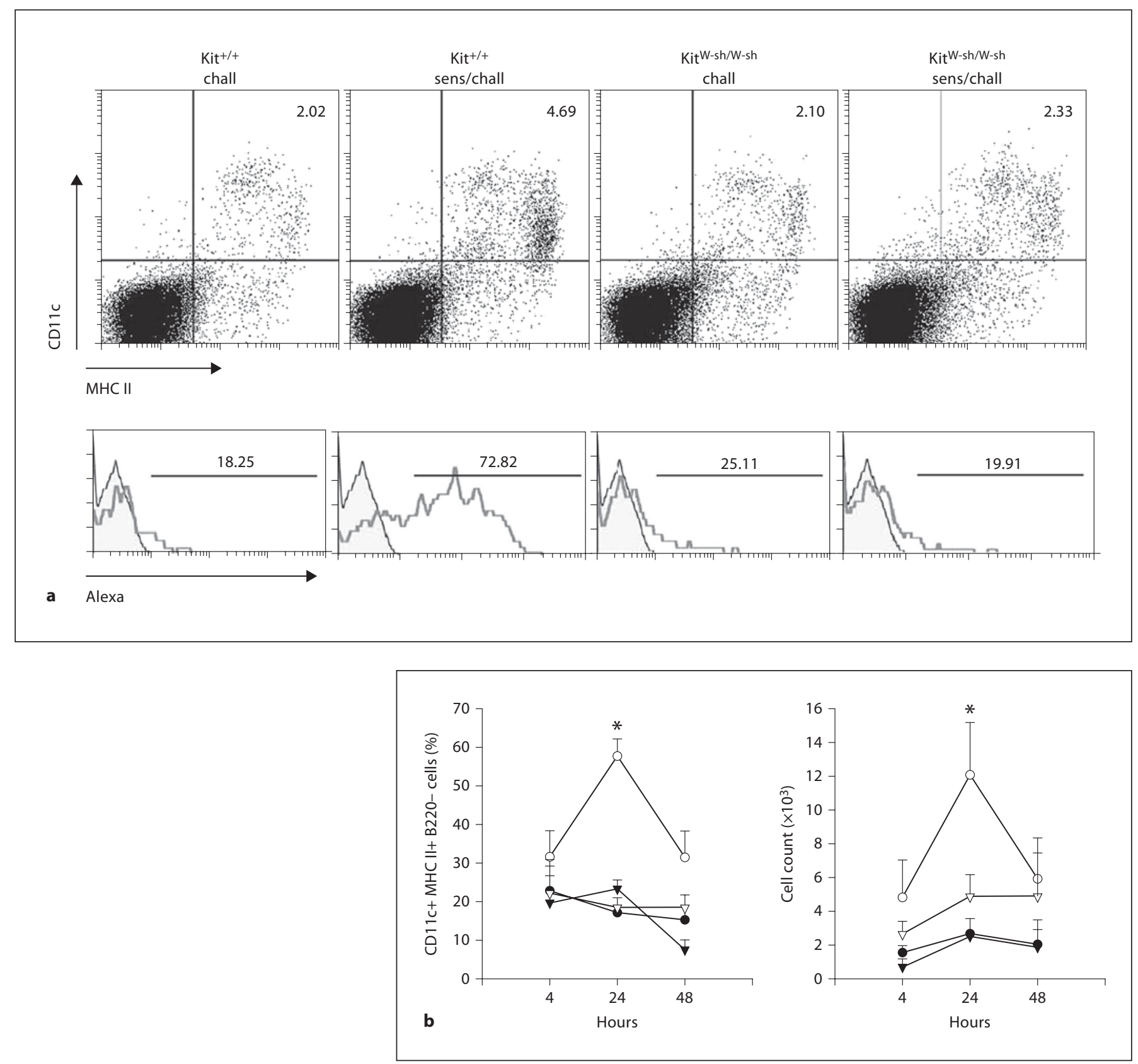

Fig. 1. Alexa staining of CD11c+ MHC II+ B220 - cells in tracheal lymph nodes. a Staining of mDCs (CD11c+ MHC II+ B220-) in the tracheal lymph nodes following administration of fluorescent-labeled OVA into the lung. Representative examples of challenged-only wild-type animals ( $\mathrm{Kit}^{+/+}$chall), sensitized and challenged wild-type animals ( $\mathrm{Kit}^{+/+}$sens/chall), challenged-only mast cell-deficient mice ( $\mathrm{Kit}^{\mathrm{W}-\mathrm{sh} / \mathrm{W} \text {-sh }}$ chall) and sensitized and challenged mast cell-deficient mice (Kit ${ }^{\mathrm{W} \text {-sh/W-sh }}$ sens/chall). Top panels show gating of CD11c+ and MHC II+ (and B220-negative) populations. Percentages of CD11c+ MHC II+ B220- cells. The bottom panel shows the intensity of Alexa staining among gated cells (light grey curve). The shaded curves show cells from tra- cheal lymph nodes of mice which did not receive OVA-Alexa. Percentages of Alexa-positive cells. b Relative and absolute numbers of Alexa-positive mDCs (CD11c+ MHC II+ B220-) in the tracheal lymph nodes at different time points following OVA-Alexa administration in challenged-only wild-type ( $\mathrm{Kit}^{+/+}$chall, closed circle) or mast cell-deficient (Kit ${ }^{\mathrm{W} \text {-sh/W-sh }}$ chall, closed triangle) and sensitized and challenged wild-type $\left(\mathrm{Kit}^{+/+}\right.$sens/chall, open circle) or mast cell-deficient animals (Kit ${ }^{\mathrm{W} \text {-sh/W-sh }}$ sens/chall, open triangle). Means \pm SEM. Results are from 2 independent experiments ( $\mathrm{n}=4$ per group for each time point). ${ }^{*} \mathrm{p}<0.05$ compared with all other groups. 


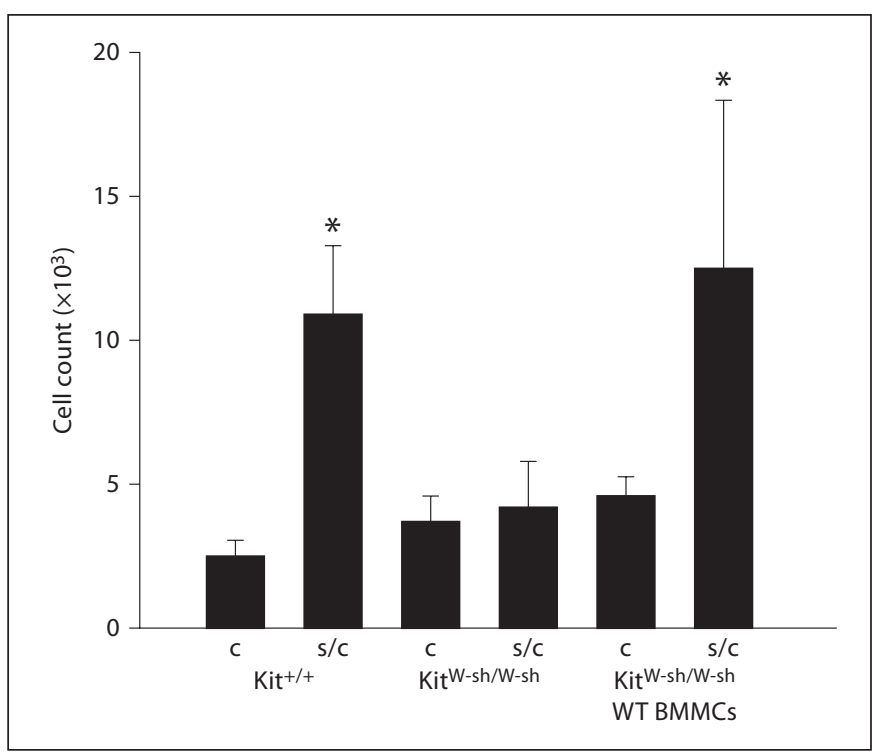

Fig. 2. Mast cell reconstitution increases the numbers of DCs in the tracheal lymph nodes. Numbers of Alexa-positive mDCs in the regional lymph nodes at $24 \mathrm{~h}$ following administration of fluorescent-labeled OVA to challenged (c) as well as sensitized and challenged (s/c) wild-type (WT) animals $\left(\mathrm{Kit}^{+/+}\right)$, mast celldeficient $\left(\mathrm{Kit}{ }^{\mathrm{W}-\mathrm{sh} / \mathrm{W} \text {-sh }}\right)$ or mast cell-deficient animals reconstituted with BMMCs from wild-type donors $\left(\mathrm{Kit}^{\mathrm{W} \text {-sh } / \mathrm{W} \text {-sh }}\right.$ wildtype BMMCs). Means \pm SEM. ${ }^{*} \mathrm{p}<0.05$ compared to $\mathrm{Kit}^{+/+} \mathrm{c}$,

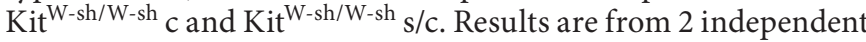
experiments ( $\mathrm{n}=8$ per group).

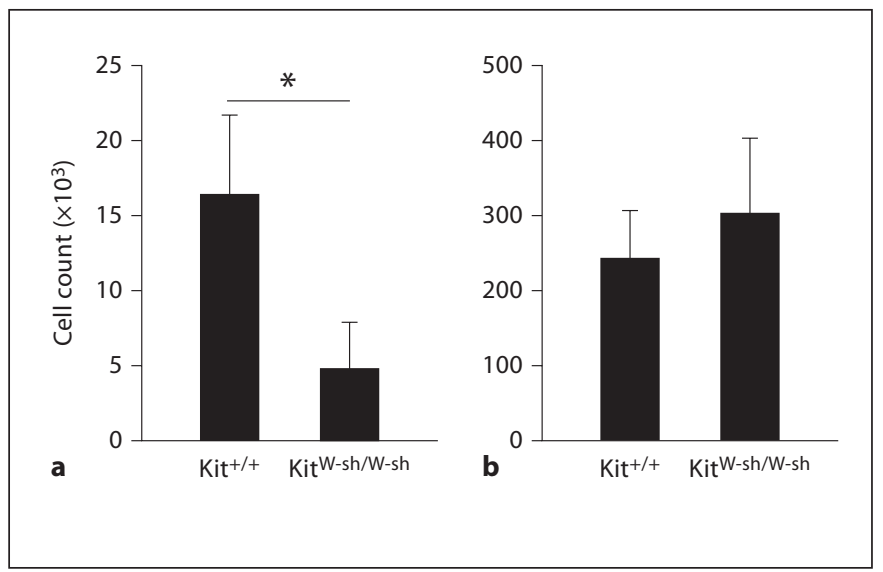

Fig. 3. Transfer of OVA-exposed BMDCs leads to aggravation of allergic airway inflammation in sensitized animals. Numbers of eosinophils in BAL fluid $48 \mathrm{~h}$ following allergen challenge. a Number of eosinophils following single intranasal allergen exposure of sensitized wild-type $\left(\mathrm{Kit}^{+/+}\right)$or mast cell-deficient (Kit $\left.{ }^{\mathrm{W}-\mathrm{sh} / \mathrm{W}-\mathrm{sh}}\right)$ mice. b Number of eosinophils following single intranasal allergen exposure of sensitized wild-type $\left(\mathrm{Kit}^{+/+}\right)$or mast cell-deficient $\left(\mathrm{Kit}^{\mathrm{W} \text {-sh/W-sh }}\right)$ mice previously treated with allergenpulsed BMDCs. Mean \pm SEM. ${ }^{*} \mathrm{p}<0.05$. Results are from 2 independent experiments ( $\mathrm{n}=8$ per group).

Table 1. Number of mast cells in lung

\begin{tabular}{|c|c|c|c|}
\hline & $\begin{array}{l}\mathrm{C} 57 \mathrm{BL} / 6-\mathrm{Kit}^{+/+} \\
\mathrm{n}=8\end{array}$ & 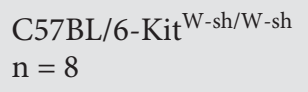 & $\begin{array}{l}\text { C57BL/6-Kit }{ }^{\mathrm{W}-\mathrm{sh} / \mathrm{W}-\mathrm{sh}} \\
\text { BMMCs, } \mathrm{n}=8\end{array}$ \\
\hline Mast cells per $\mathrm{cm}^{2}$ & $23 \pm 5$ & ND & $28 \pm 11$ \\
\hline
\end{tabular}

Mast cells were stained in lung tissue as described in Materials and Methods in wild type animals $\left(\mathrm{C} 57 \mathrm{BL} / 6-\mathrm{Kit}^{+/+}\right)$, mast cell deficient mice $\left(\mathrm{C} 57 \mathrm{BL} / 6-\mathrm{Kit}{ }^{\mathrm{W}-\mathrm{sh} / \mathrm{W}-\mathrm{sh}}\right)$ and mast cell deficient mice reconstituted with bone marrow derived mast cells (C57BL/

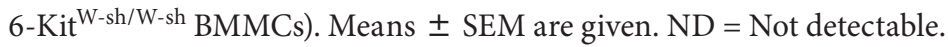

mined the influx of eosinophils into the airways. In previous studies, the numbers of eosinophils in BAL fluid were lower in mast cell-deficient animals compared with wild-type animals [8]. To assess the effect of allergen-exposed DCs in this setting, BMDCs were cultured from bone marrow of wild-type and mast cell-deficient animals. BMDCs were incubated in vitro with OVA, which leads to cell maturation, detectable by increased expression of MHC II, CD40, CD80, and CD86 on the cell surface. These cells were then administered intranasally to sensitized C57BL/6-Kit ${ }^{\mathrm{W}-\text {-sh/W-sh }}$ mice or their wild-type counterparts 1 day prior to airway challenge. In accordance with previous studies, airway inflammation as a result of intranasal OVA exposure of sensitized animals was only elicited in wild-type mice but not in mast celldeficient C57BL/6-Kit ${ }^{\mathrm{W}-s h / \mathrm{W}-s h}$ mice (fig. 3a). Sensitized and challenged animals which received unpulsed BMDCs prior to the challenge showed eosinophil numbers comparable to sensitized and challenged wild-type animals which received no BMDCs. However, sensitized 


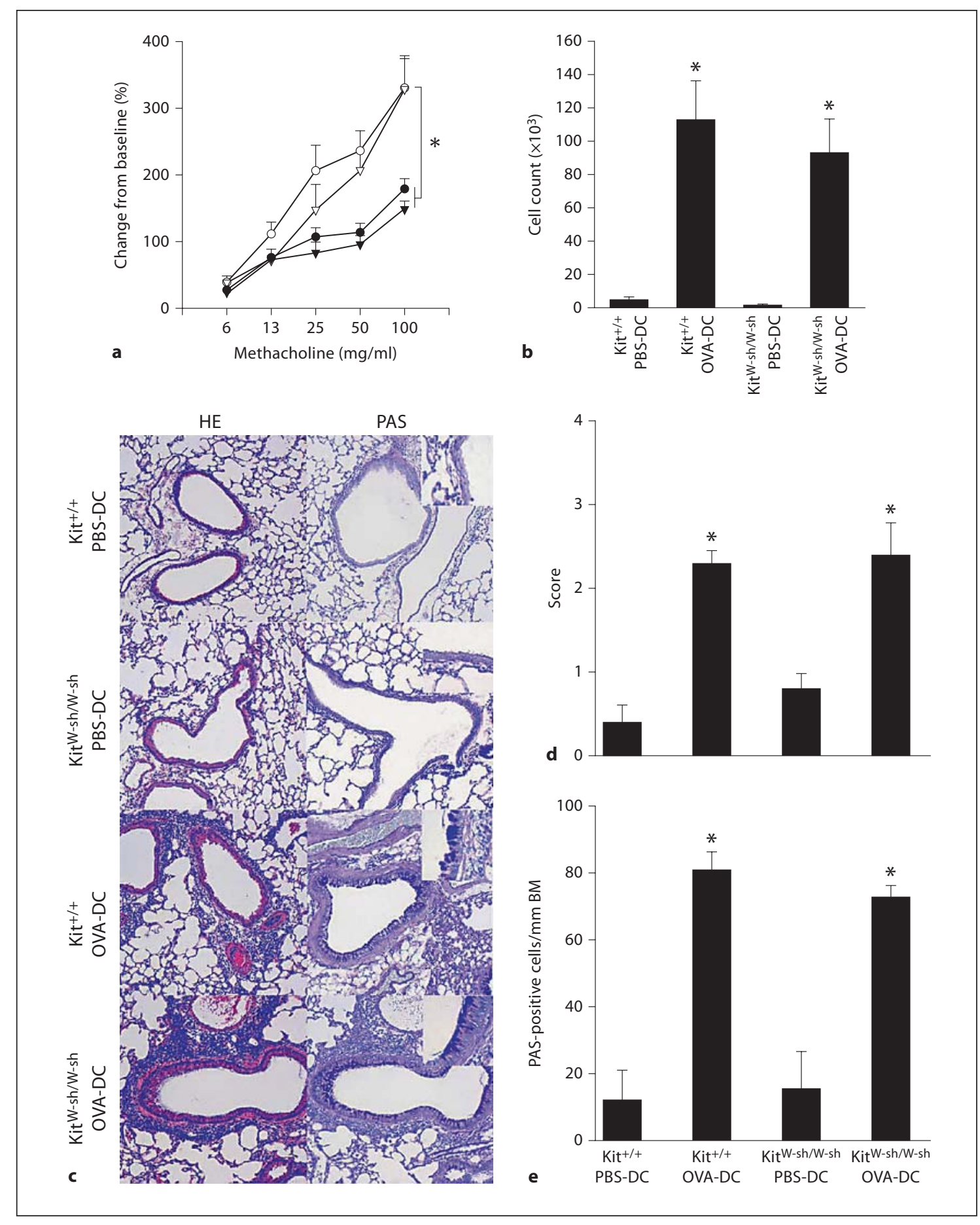

Fig. 4. Transfer of OVA-exposed DCs to nonsensitized mice and consecutive airway challenge lead to allergic airway disease in wild-type and mast cell-deficient animals. Wild-type animals $\left(\mathrm{Kit}^{+/+}\right)$and mast cell-deficient mice (Kit ${ }^{\mathrm{W}-\mathrm{sh} / \mathrm{W} \text {-sh})}$ received unpulsed BMDCs (PBS-DC) or OVA-pulsed BMDCs (OVA-DC) and were subsequently challenged as described in Materials and Methods. Airway reactivity as change in airway resistance (RL) (a) was assessed in $\mathrm{Kit}^{+/+}$PBS-DC (closed circle), $\mathrm{Kit}^{+/+}$ OVA-DC (open circle), Kit ${ }^{\mathrm{W}-\mathrm{sh} / \mathrm{W} \text {-sh }}$ PBS-DC (closed triangle) and

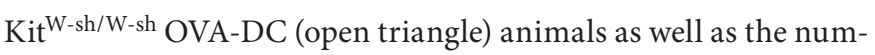
ber of eosinophils in BAL fluid (b). Baseline values were not statistically different between groups. Tissue inflammation was evaluated $48 \mathrm{~h}$ following the last challenge using HE and PAS staining for goblet cells (c). Tissue inflammation (d) and number of goblet cells (e) were scored as described in Materials and Methods. Means \pm SEM. ${ }^{*} \mathrm{p}<0.01$. Results are from 2 independent experiments ( $\mathrm{n}=8$ per group). 


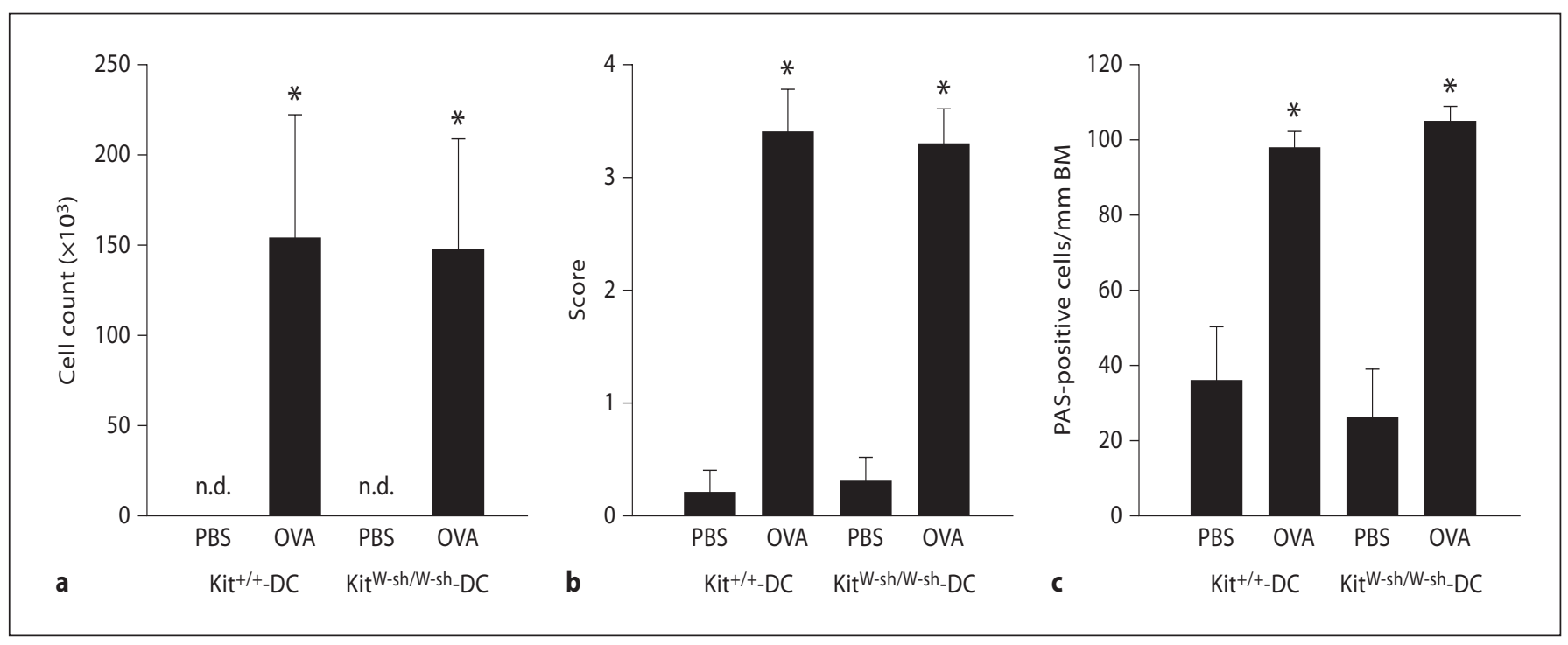

Fig. 5. Transfer of OVA-exposed DCs derived from wild-type or mast cell-deficient animals are equally effective in inducing allergic airway disease in wild-type animals. Wild-type animals received unpulsed BMDCs (PBS) or OVA-pulsed BMDCs (OVA) from either wild-type ( $\mathrm{Kit}^{+/+}$-DC) or mast cell-deficient $\left(\mathrm{Kit}^{\mathrm{W}}{ }^{-\mathrm{sh}} / \mathrm{W}\right.$-sh $\left.-\mathrm{DC}\right)$ donors and were subsequently challenged as de- scribed in Materials and Methods. Numbers of eosinophils in BAL fluid (a), tissue inflammation score using HE staining (b) and goblet cell numbers using PAS staining (c) were evaluated $48 \mathrm{~h}$ following the last challenge. Means \pm SEM. ${ }^{*} \mathrm{p}<0.05 \mathrm{com}-$

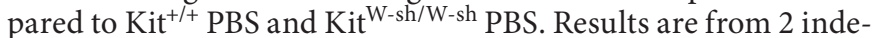
pendent experiments ( $\mathrm{n}=6$ per group). and challenged wild-type mice which received OVApulsed BMDCs showed a strong increase in eosinophil numbers in BAL fluid (fig. 3b), especially when compared to sensitized and challenged mice which did not receive BMDCs (fig. 3a). Most important, mast cell-deficient mice also showed a strong increase in the numbers of BALeosinophils following administration of OVA-pulsed DCs prior to challenge, comparable with wild-type animals under these conditions (fig. $3 b$ ).

\section{Sensitization with Allergen-Pulsed DCs Induces}

\section{Allergic Airway Disease Independently of Mast Cells}

The results described above imply that the function of mast cells for the generation of an inflammatory response in allergen-experienced animals can be bypassed by transfer of mature BMDCs loaded with the allergen. Consequently, we next investigated the effect of allergen-laden BMDCs following their transfer in nonsensitized recipients. To this end, BMDCs were incubated with OVA in vitro and then applied intranasally in mast cell-deficient mice and their congenic mast cell-competent littermates on day 0 . Then, mice were challenged on days 10-12 via allergen inhalation. As expected, wild-type animals showed AHR (fig. 4a), increased numbers of eosinophils in the BAL fluid (fig. $4 \mathrm{~b}$ ) and also increased tis- sue inflammation and goblet cell metaplasia (fig. 4c-e) as compared with animals receiving unpulsed BMDCs. However, the administration of allergen-pulsed BMDCs prior to allergen challenge led to the development of fullblown airway inflammation and AHR in mast cell-deficient mice (fig. 4). To exclude impaired DC functions in mast cell-deficient mice, these experiments were also done using BMDCs derived from C57BL/6-Kit ${ }^{\mathrm{W}-\mathrm{sh} / \mathrm{W} \text {-sh }}$ animals, with comparable results (fig. 5).

\section{Discussion}

Previous studies have shown that the development of airway inflammation and AHR following sensitization without an additional adjuvant is dependent on mast cells $[3,7,8,21]$ and has been linked to mediators produced by mast cells like TNF $[7,8]$. However, the underlying mechanisms mediated by mast cells are incompletely understood, and different effects like local activation of Th2 cells [7] or migration of effector T cells into the lung [22] have been implicated. We demonstrated in the present study that following administration of an allergen, migration of DCs from the lung to the mediastinal lymph nodes is increased in sensitized wild-type animals. In contrast 
to these findings, the numbers of allergen-laden DCs in sensitized mast cell-deficient mice are much lower. Similar to the findings in the present study, Nakae et al. [7] found decreased numbers of fluorescent DCs at $24 \mathrm{~h}$ following administration of fluorescent-labeled antigen to sensitized mast cell-deficient animals. Following mast cell reconstitution, the number of fluorescent DCs in the regional lymph nodes was comparable to that in wild-type animals in their study, suggesting that mast cells in the sensitized hosts directly contribute to the migration of allergen-exposed DCs from the lung to the thoracic lymphoid tissue. Previous studies have demonstrated that following allergen exposure of sensitized mice, increased allergen uptake and processing by DCs in the conducting airways is allergen-specific and can be transferred by passive immunization, suggesting the involvement of immunoglobulins [23]. This further supports a potential role of mast cells as these cells express Fc $\gamma$ receptors as well as the high-affinity IgE receptor (FceRI). Indeed, previous studies using an inhalation exposure model have demonstrated that mast cells and expression of FceRI are critical for the development of increased airway reactivity [24].

It has been argued that migration of airway DCs to the draining lymph nodes is necessary to provide a functional $\mathrm{T}$ cell signal and response [25]. Indeed, studies of repeated airway challenges have elegantly demonstrated that DCs are crucial for the induction of recall responses in sensitized hosts [11]. Based on the present findings, it can be suggested that mast cells contribute to adequate activation of DCs, resulting in increased antigen uptake and migration to the regional lymph nodes. Indeed, sensitized animals deficient in mast cells $\left(\mathrm{WBB}_{1} \mathrm{~F}_{1}-\mathrm{Kit}^{\mathrm{W} / \mathrm{Wv}}\right.$ and $\mathrm{C} 57 \mathrm{BL} / 6-\mathrm{Kit}{ }^{\mathrm{W}}$-sh/W-sh $)$ not only showed impaired migration of DCs to the regional lymph nodes, but also the development of airway inflammation was reduced in these animals, similar to previous reports in different allergen exposure models $[3,7,8,21,24]$. However, in the present study, we assessed the migration of DCs and no other markers of DC activation or priming. Yet, there is no obvious difference between wild-type and mast celldeficient mice at least with regard to the levels of MHC II expression on DCs (fig. 1a). Future work will focus on whether mast cells also influence other parameters of DC priming, especially antigen degradation and processing. Mast cell-derived mediators activating BMDCs may encompass TNF and IL-1 $\beta$, which have been shown before to mediate DC maturation [16] and migration [26], and especially TNF produced by mast cells has been linked to the development of allergic airway disease $[7,8]$. These findings with the present, probably less potent, sensitiza- tion protocols without adjuvant again demonstrate that mast cells are essential for the development of allergic airway disease. Interestingly, the transfer of allergen-exposed BMDCs prior to the pulmonary challenge leads to massive airway inflammation. Indeed, following the administration of allergen-exposed BMDCs, both sensitized wild-type and mast cell-deficient animals showed a massive influx of eosinophils into the airways. These results demonstrate that once allergen-exposed DCs are activated, mast cells are no longer necessary to induce allergic airway disease. This finding confirms the notion that the significance of mast cells in the development of allergic airway disease depends on the model used.

This observation is further strengthened by the results obtained in a model of sensitization via the airways using allergen-pulsed BMDCs [27]. Administration of allergenpulsed BMDCs into the lungs of mice and subsequent allergen challenge led to airway inflammation and development of AHR. This was also the case when allergenpulsed BMDCs were administered to mast cell-deficient recipients, again showing that if DCs are already activated, mast cells are no longer needed to induce allergic airway disease.

Recently, it has been reported that DCs cultured from $\mathrm{Kit}^{\mathrm{W} / \mathrm{Wv}}$ animals are less capable of inducing allergic airway disease in the lung [28]. In the present study, BMDCs

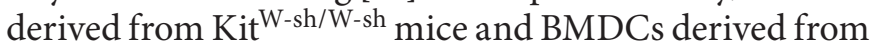
wild-type animals were similarly effective in inducing allergic airway disease following intratracheal administration and allergen challenge. These findings are consistent with data showing that antigen-laden BMDCs from

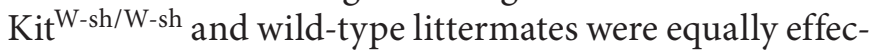
tive in mounting a full-blown cytotoxic $\mathrm{T}$ lymphocytes response in C57BL/6 mice [13]. These somewhat diverse findings might be due to differences in the mouse strains used, as dramatically different responses to immune complex-mediated arthritis were observed in $\mathrm{Kit}^{\mathrm{W}-\mathrm{sh} / \mathrm{W} \text {-sh }}$ and $\mathrm{Kit}^{\mathrm{W} / \mathrm{Wv}_{\mathrm{v}}}$ animals [29]. In summary, the present study shows that following allergen challenge, migration of DCs from the lung to the regional lymph nodes in sensitized hosts is dependent on mast cells. This is a crucial step in the development of allergic airway inflammation. However, once DCs are activated, mast cells are no longer necessary for the initiation of allergic airway disease.

\section{Acknowledgements}

This study was funded by DFG SFB 548 A10 (M.S.), A11 (C.T.), B5 (S.S., A.B.R.-K.), DFG STA 984/1-1 (M.S) and DFG TA 275/4-1 (C.T., M.S.). 


\section{References}

1 Taube C, Dakhama A, Gelfand EW: Insights into the pathogenesis of asthma utilizing murine models. Int Arch Allergy Immunol 2004;135:173-186.

-2 Brightling CE, Bradding P, Symon FA, Holgate ST, Wardlaw AJ, Pavord ID: Mast-cell infiltration of airway smooth muscle in asthma. N Engl J Med 2002;346:1699-1705.

3 Williams CM, Galli SJ: Mast cells can amplify airway reactivity and features of chronic inflammation in an asthma model in mice. J Exp Med 2000;192:455-462.

4 Yu CK, Chen CL: Activation of mast cells is essential for development of house dust mite Dermatophagoides farinae-induced allergic airway inflammation in mice. J Immunol 2003;171:3808-3815

5 Galli SJ, Nakae S, Tsai M: Mast cells in the development of adaptive immune responses. Nat Immunol 2005;6:135-142.

6 Bryce PJ, Mathias CB, Harrison KL, Watanabe T, Geha RS, Oettgen $\mathrm{HC}$ : The $\mathrm{H}_{1}$ histamine receptor regulates allergic lung responses. J Clin Invest 2006;116:1624-1632.

7 Nakae S, Ho LH, Yu M, Monteforte R, Iikura M, Suto H, Galli SJ: Mast cell-derived TNF contributes to airway hyperreactivity, inflammation, and Th2 cytokine production in an asthma model in mice. J Allergy Clin Immunol 2007;120:48-55.

$>8$ Reuter S, Heinz A, Sieren M, Wiewrodt R, Gelfand EW, Stassen M, Buhl R, Taube C: Mast cell-derived tumour necrosis factor is essential for allergic airway disease. Eur Respir J 2008;31:773-782.

$\checkmark 9$ Hammad H, Lambrecht BN: Lung dendritic cell migration. Adv Immunol 2007;93:265278.

10 Hammad H, Lambrecht BN: Dendritic cells and epithelial cells: linking innate and adaptive immunity in asthma. Nat Rev Immunol 2008;8:193-204.

-11 van Rijt LS, Jung S, Kleinjan A, Vos N, Willart M, Duez C, Hoogsteden HC, Lambrecht $\mathrm{BN}$ : In vivo depletion of lung CD11c+ dendritic cells during allergen challenge abrogates the characteristic features of asthma. J Exp Med 2005;201:981-991.

-12 Hammad H, Kool M, Soullié T, Narumiya S, Trottein F, Hoogsteden HC, Lambrecht BN: Activation of the D prostanoid 1 receptor suppresses asthma by modulation of lung dendritic cell function and induction of regulatory T cells. J Exp Med 2007;204:357-367.
13 Heib V, Becker M, Warger T, Rechtsteiner G, Tertilt C, Klein M, Bopp T, Taube C, Schild $\mathrm{H}$, Schmitt E, et al: Mast cells are crucial for early inflammation, migration of Langerhans cells, and CTL responses following topical application of TLR7 ligand in mice. Blood 2007;110:946-953.

14 Suto H, Nakae S, Kakurai M, Sedgwick JD, Tsai M, Galli SJ: Mast cell-associated TNF promotes dendritic cell migration. J Immunol 2006;176:4102-4112.

15 Idzko M, Panther E, Corinti S, Morelli A Ferrari D, Herouy Y, Dichmann S, Mockenhaupt M, Gebicke-Haerter P, Di Virgilio F, et al: Sphingosine 1-phosphate induces chemotaxis of immature and modulates cytokinerelease in mature human dendritic cells for emergence of Th2 immune responses. FASEB J 2002; 16:625-627.

16 Bros M, Jährling F, Renzing A, Wiechmann N, Dang NA, Sutter A, Ross R, Knop J, Sudowe S, Reske-Kunz AB: A newly established murine immature dendritic cell line can be differentiated into a mature state, but exerts tolerogenic function upon maturation in the presence of glucocorticoid. Blood 2007;109: 3820-3829.

17 Lambrecht BN, Pauwels RA, Fazekas De St Groth B: Induction of rapid T cell activation, division, and recirculation by intratracheal injection of dendritic cells in a TCR transgenic model. J Immunol 2000;164:29372946.

18 Bergstresser PR, Tigelaar RE, Tharp MD: Conjugated avidin identifies cutaneous rodent and human mast cells. J Invest Dermatol 1984;83:214-218.

19 Bussolati G, Gugliotta P: Nonspecific staining of mast cells by avidin-biotin-peroxidase complexes (ABC). J Histochem Cytochem 1983;31:1419-1421.

20 Bopp T, Dehzad N, Reuter S, Klein M, Ullrich N, Stassen M, Schild H, Buhl R, Schmitt E, Taube C: Inhibition of cAMP degradation improves regulatory $\mathrm{T}$ cell-mediated suppression. J Immunol 2009;182:4017-4024.

-21 Yu M, Tsai M, Tam SY, Jones C, Zehnder J, Galli SJ: Mast cells can promote the development of multiple features of chronic asthma in mice. J Clin Invest 2006;116:1633-1641.
22 Taube C, Miyahara N, Ott V, Swanson B, Takeda K, Loader J, Shultz LD, Tager AM, Luster AD, Dakhama A, et al: The leukotriene $B_{4}$ receptor (BLT1) is required for effector CD8+ T cell-mediated, mast cell-dependent airway hyperresponsiveness. J Immunol 2006;176:3157-3164.

23 von Garnier C, Wikstrom ME, Zosky G, Turner DJ, Sly PD, Smith M, Thomas JA, Judd SR, Strickland DH, Holt PG, et al: Allergic airways disease develops after an increase in allergen capture and processing in the airway mucosa. J Immunol 2007; 179 : 5748-5759.

24 Taube C, Wei X, Swasey CH, Joetham A, Zarini S, Lively T, Takeda K, Loader J, Miyahara N, Kodama T, et al: Mast cells, FceRI, and IL-13 are required for development of airway hyperresponsiveness after aerosolized allergen exposure in the absence of adjuvant. J Immunol 2004;172:6398-6406.

25 Stumbles PA, Thomas JA, Pimm CL, Lee PT, Venaille TJ, Proksch S, Holt PG: Resting respiratory tract dendritic cells preferentially stimulate T helper cell type 2 (Th2) responses and require obligatory cytokine signals for induction of Th1 immunity. J Exp Med 1998; 188:2019-2031.

26 Cumberbatch M, Dearman RJ, Antonopoulos C, Groves RW, Kimber I: Interleukin (IL)18 induces Langerhans cell migration by a tumour necrosis factor- $\alpha$ - and IL- $1 \beta$-dependent mechanism. Immunology 2001;102: 323-330.

27 Lambrecht BN, De Veerman M, Coyle AJ, Gutierrez-Ramos JC, Thielemans K, Pauwels RA: Myeloid dendritic cells induce Th2 responses to inhaled antigen, leading to eosinophilic airway inflammation. J Clin Invest 2000;106:551-559.

28 Krishnamoorthy N, Oriss TB, Paglia M, Fei M, Yarlagadda M, Vanhaesebroeck B, Ray A, Ray P: Activation of c-Kit in dendritic cells regulates T helper cell differentiation and allergic asthma. Nat Med 2008;14:565573.

29 Zhou JS, Xing W, Friend DS, Austen KF, Katz HR: Mast cell deficiency in Kit(W-Sh) mice does not impair antibody-mediated arthritis. J Exp Med 2007;204:2797-2802. 